\title{
Decentralizing healthcare in Norway to improve patient-centered outpatient clinic management of rheumatoid arthritis - a conceptual model
}

\author{
Alen Brkic ${ }^{1 *}$ (D) Jung G. Kim², Glenn Haugeberg ${ }^{3}$ and Andreas P. Diamantopoulos ${ }^{4,5}$
}

\begin{abstract}
A growing population of older adults and improved effective treatments for inflammatory rheumatic diseases will increase the demand for more healthcare resources that already struggle with staggering outpatient clinic waiting times. Transformative delivery care models that provide sustainable healthcare services are urgently needed to meet these challenges. In this mini-review article, a proposed Lifelong Treatment Model for a decentralized followup of outpatient clinic patients living with rheumatoid arthritis is presented and discussed. Our conceptual model follows four steps for a transformative care delivery model supported by an Integrated Practice Unit; (1) Diagnosis, (2) Treatment, (3) Patient Empowered Disease Management, and (4) Telehealth. Through an Integrated Practice Unit, a multidisciplinary team could collaborate with patients with rheumatoid arthritis to facilitate high-value care that addresses most important outcomes of the patients; (1) Early Remission, (2) Decentralization, (3) Improved Quality of Life, and (4) Lifelong Sustain Remission.

The article also addresses the growing challenges for the healthcare delivery system today for patients with rheumatoid arthritis and proposes how to reduce outpatient clinic visits without compromising quality and safety.
\end{abstract}

Keywords: Decision making, Chronic disease management, Telehealth, Empowerment, Rheumatology, Cost reduction, COVID, Patient-centeredness

\section{Background}

This paper proposes a "lifelong treatment model" for rheumatoid arthritis (RA) patients to meet the increasing challenges of the growing waiting list at outpatient clinics and indicate the pressure for healthcare systems to care for their patient populations. The proposed model seeks to maximize efficient use of resources, e.g., clinical visits for RA patients in remission or low disease activity, without compromising safety and quality through a decentralized follow-up and self-monitoring

\footnotetext{
*Correspondence: 107alen@gmail.com

'Department of Research, Sorlandet Hospital, Service Box 416, Kristiansand, Norway

Full list of author information is available at the end of the article
}

care model using telehealth and innovative electronic tools. Figure 1, the lifelong RA patient treatment model and Fig. 2, the Integrated Practice Unit (IPU) depicts our conceptual model and describes the interaction between the IPU, patient and primary care physicians.

Rheumatoid arthritis (RA) is a systemic autoimmune chronic inflammatory disorder primarily involving small joints of hands and feet [1]. The disease consequence for the patients includes, e.g., pain, joint stiffness, physical impairments, and fatigue that reduces the health-related quality of life (HRQoL) [2, 3]. Significant improvement in disease outcome of RA patients has been reported recently, driven by improved treatment strategies (early treatment and treating patients to target) and new drugs

(C) The Author(s). 2021 Open Access This article is licensed under a Creative Commons Attribution 4.0 International License, which permits use, sharing, adaptation, distribution and reproduction in any medium or format, as long as you give appropriate credit to the original author(s) and the source, provide a link to the Creative Commons licence, and indicate if changes were made. The images or other third party material in this article are included in the article's Creative Commons licence, unless indicated otherwise in a credit line to the material. If material is not included in the article's Creative Commons licence and your intended use is not permitted by statutory regulation or exceeds the permitted use, you will need to obtain permission directly from the copyright holder. To view a copy of this licence, visit http://creativecommons.org/licenses/by/4.0/. The Creative Commons Public Domain Dedication waiver (http://creativecommons.org/publicdomain/zero/1.0/) applies to the data made available in this article, unless otherwise stated in a credit line to the data. 


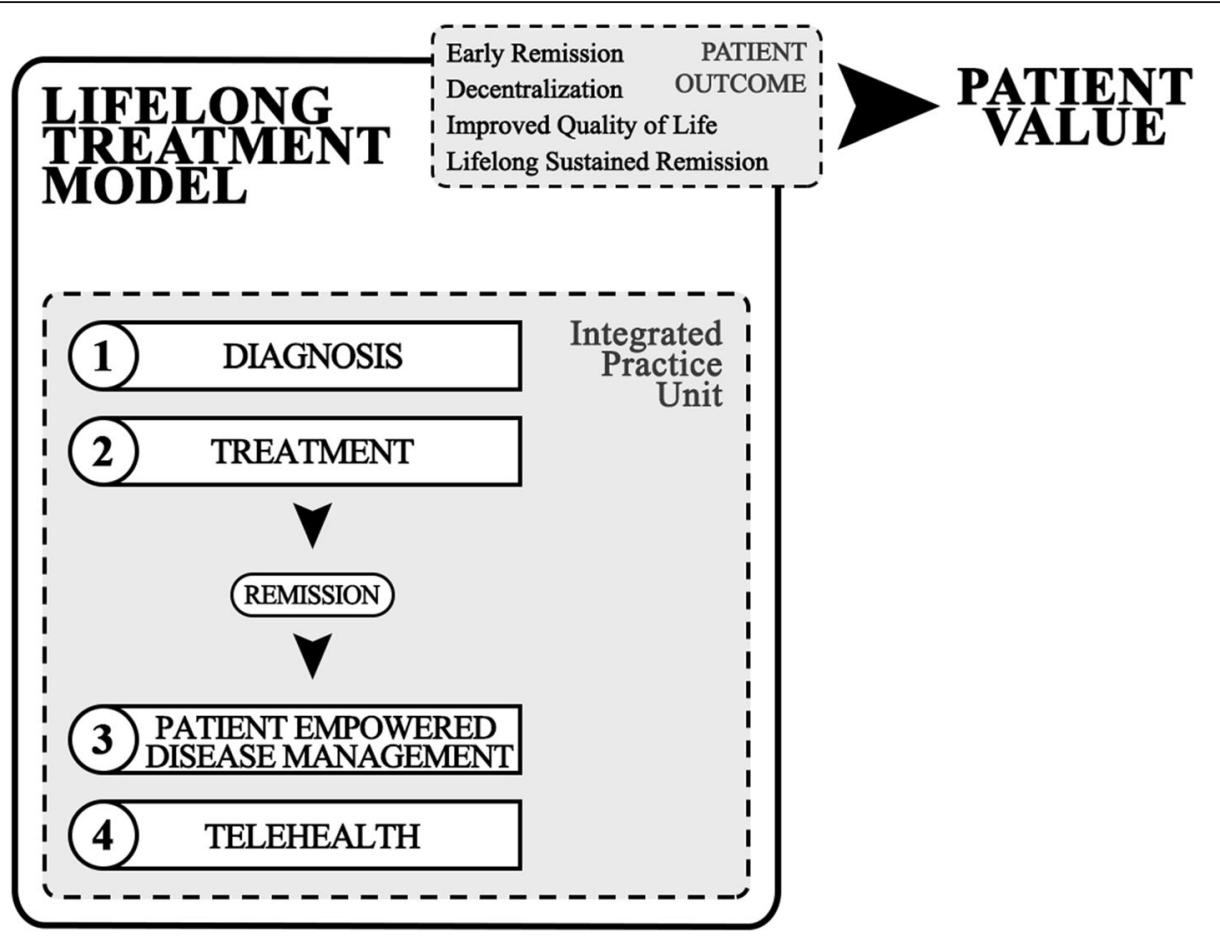

Fig. 1 The lifelong rheumatoid arthritis patient treatment model. Legend: Not Applicable

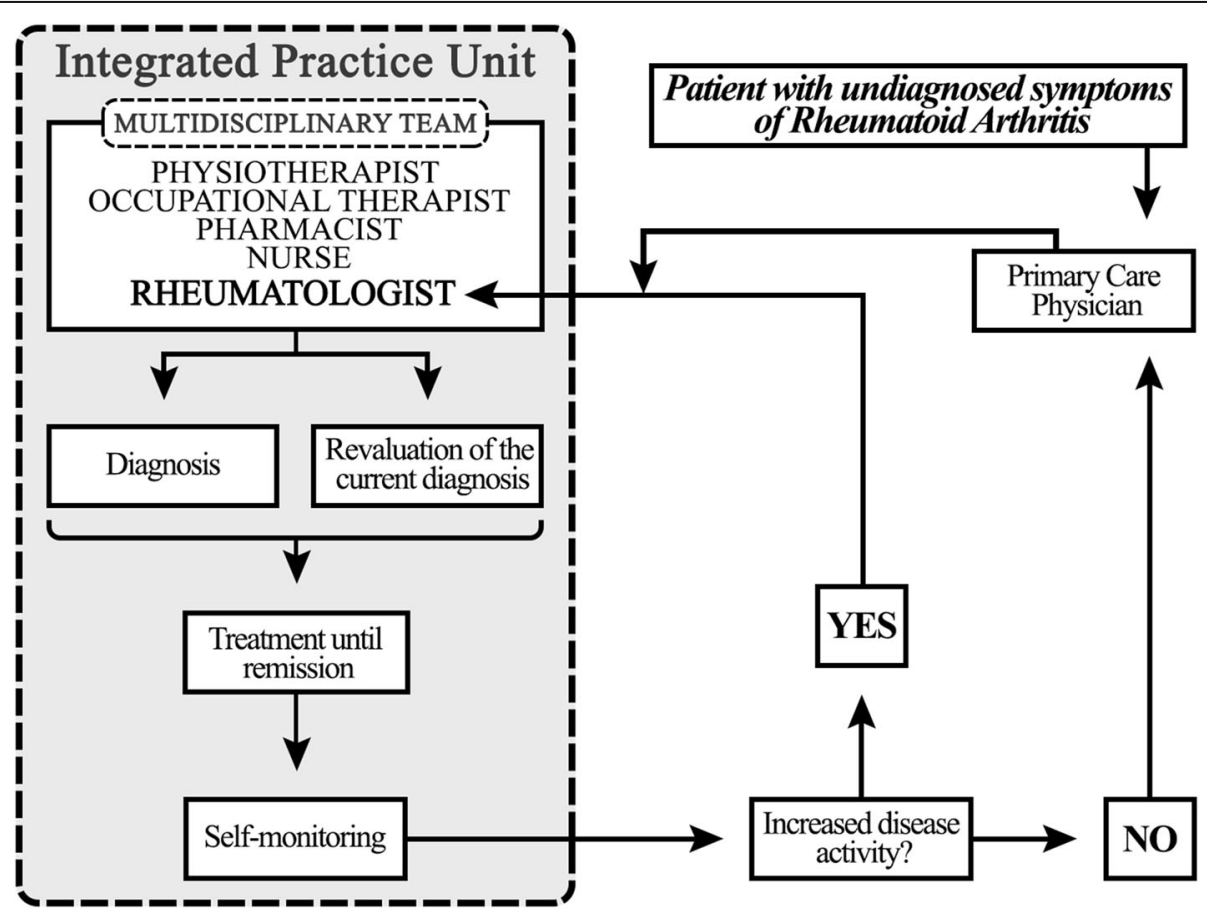

Fig. 2 The Integrated Practice Unit (IPU) plan for patients with rheumatoid arthritis. Legend: Not Applicable 
[4-7]. Consequently, there has been a shift in rheumatology from inpatient to outpatient clinic follow-up, thus, reducing the need for hospital beds substantially. With the reduction of hospital beds, inpatient costs have been reduced, whereas outpatient-based medication usage and costs for RA have increased. For example, in Norway from 2006 to 2018, the number of offered biological treatments increased from 7650 to 34,000 [8]. With the shift from inpatient to outpatient follow-up of patients treated with expensive and potentially harmful drugs, the number of outpatient clinic visits has increased, challenging the capacity of the healthcare system. With the growing outpatient population needing care, the wait times are increasing [9]. The COVID-19 pandemic has shown how vulnerable healthcare system resources are and highlights the need and opportunities to organize and deliver healthcare services, e.g., telehealth. Further, considering the global lockdown of healthcare systems due to the COVID-19 pandemic, the proliferation of waiting lists may be exponentially higher than in previous years [10].

Compared to nurse-led outpatient clinics, patientcentered methods have shown that implementing patient-initiated and patient-self-monitored approaches among RA patients reduces the usage of primary and secondary healthcare services without compromising patient's clinical and psychosocial well-being [9]. As observed with patient care for epilepsy, telehealth alone improved patient-reported outcomes versus face-to-face follow-up care, and saves roughly half of the patient population from physical outpatient follow-up visits [11].

The growing number of RA patients now in remission also challenges the conventional monitoring of patients through face-to-face visits [7]. However, telehealth strategies can reduce the number of conventional face-toface consultations without sacrificing improved disease outcomes among RA patients with low disease activity or remission [12].

Thus, there is an imminent need for a different management approach for the overall outpatient population to meet the growing challenges of the healthcare system driven by an aging population and new treatment options for RA. This need is also reflected in long-term strategies addressing the need to transform the healthcare system, including innovative patient-friendly telehealth solutions. The need for a healthcare delivery that is decentralized has been further increased in light of the COVID-19 pandemic [13-18].

In this paper, we propose a conceptual model for decentralizing the Norwegian healthcare system and optimizing patient-centeredness for RA through strategic organizational management principles. The proposal utilizes Porter's Hierarchy of Outcome model [19] applied to the RA care setting and adjusted for administration through a decentralized approach to promote high-value care through an Integrated Practice Unit.

\section{Main text \\ Addressing the changing rheumatoid arthritis care model in Norway}

Strategic planning in the management sector has been incorporated to identify high-value methods for the enduser. In healthcare, the end-users are the patients, and the high-value methods enhance their treatment efficiency and maximize healthcare resources. Healthcare value is defined as optimizing patient outcomes proportional to the health system costs of achieving those outcomes [20]. Identifying and implementing high-value care is crucial in the rapidly changing RA treatment setting [20].

The fundamental driving component of increasing value for the patient is identifying the specific outcomes to operationalize value based on the patient's perspective. In the case of care of RA patients in the Norwegian health system, the primary patient outcomes would focus on early remission (preventing irreversible joint damage), improved HRQoL while maintaining sustained remission throughout the patient's life, and reducing patient dependence on hospital settings after achieving remission. These factors providing value to the RA patient and achieving optimal patient-centered management need to be systematically addressed (Fig. 1).

To achieve early RA remission, precise diagnosis and rapid evaluation are priorities. Both require a rapidresponse strategy that is orientated to care for newly diagnosed or relapsing patients. Initiation of RA treatment within the first 3 months of diagnosis leads to the best possible outcomes, making the quick evaluation and treatment initiation a central feature in remission [21].

Quality of life (QoL) is the ability to enjoy life on a day-to-day basis despite the circumstances of having an illness. Increasing QoL depends on a patient's ability to be in charge of their health and health-related environment [22-24]. While empowerment methods are related to improving QoL, not everyone is equally susceptible or autonomous in their decision-making [24-26]. Therefore, it is essential to consider the older adults and those with various degrees of cognitive impairment when assessing how to promote empowerment and implement telehealth among a patient population [27-29]. Patientinitiated and patient-controlled follow up, as well as patient-monitored treatment and laboratory tests, are all varieties of patient empowerment. Previous reports indicate that the various patient empowerment strategies effectively reduce waiting lists while maintaining disease stability without compromising the HRQoL of patients $[9,30]$. 
When sustained remission is attained, where the patient has reached a suppressed state of disease activity or at least minimal disease activity, consistent monitoring of symptoms and therapeutically changes (due to biological side-effects and increased tolerance) is expected for a lifetime among RA patient [31]. Thus, the clinical provider is required to monitor the patient consistently. Incorporating strategies to facilitate patient-centeredness and empowerment may help leverage this increased demand and provide assurance and help patients maintain remission for RA. This strategy may require the incorporation of novel solutions like telehealth to facilitate the decentralized approach. Telehealth programs have also been implemented efficiently in the setting of the COVID-19 pandemic, where decentralization is necessary [13-18].

Reducing hospital dependency is achieved by decentralizing the decision-making away from the outpatient follow-ups at hospitals to a distant disease activity monitoring setup. This goal should also incorporate resource sustainability for a healthcare system that relies on multiple strategic decision-making levels. Decentralizing the management of rheumatology care is in its infancy [32, 33], however other fields worldwide have reported various degrees of effectiveness [34-38]. These reports emphasize that efficient processes in conjunction with effective innovation (e.g., effective treatments) work in tandem to improve outcomes.

\section{A proposed lifelong treatment model The integrated practice unit}

The chronic nature of RA requires a Lifelong Treatment Model (Fig. 1). This model commences with a patient living with undiagnosed symptoms of RA and decides to seek help at their primary care physician (PCP). The patient is referred to a rheumatologist for early diagnosis and treated until remission is achieved. The treatment management transpires with the support of the IPU (Fig. 2).

With the increasing demands on outpatient services for RA treatments, high-value care for RA patients may require delivery reforms that integrate services across the healthcare system in addition to telehealth. A multidisciplinary care team [39] (e.g., RA: rheumatologists, physiotherapists, occupational therapists, pharmacists, and nurses) would combine outpatient-based and inpatient-based systems with the overarching goal to achieve and maintain sustained disease remission in partnership with the patient. An IPU within the multidisciplinary care team is an essential component in the strategy and the intersection between the two delivery systems that operated within Norway.

The main IPU's objective is to increase patient QoL and empowerment, improve disease outcomes, and leverage the entire healthcare team to contend with the increasing demand for clinical services. The current approach in Norway cannot achieve optimal patient value through one rheumatologist specialist in every local hospital to serve every rheumatologic patient's needs. The IPU should incorporate features of an integrated healthcare system with enough patient volume, high-end equipment, and established clinical decision-making guidelines and thus, should be implemented in regional or tertiary hospitals to utilize the features and resources in a healthcare delivery system. Relocating the newly diagnosed RA patient through an outpatient rheumatologic clinic organized by an IPU would be particularly meaningful in efficiently serving a higher number of patients. The idea is to apply shared decision-making between the patient and their PCPs through the IPU's guidance, model, and education. Assisting by telehealth technology, the IPU guides the RA patients to manage their disease and encourages them to self-monitor their health. At any point, if the patient struggles with symptoms that are unrelated to RA relapse, the patient can be supported by the IPU to overcome these challenges. However, if there are symptoms of increased disease activity, the patient can be referred back to the rheumatologist until the disease is once more in remission.

\section{Steps 1 \& 2: diagnosis and treatment}

The first step of the model starts at the point of diagnosis, and according to the European League Against Rheumatism (EULAR), it should be made as soon as possible through clinical examination. Once the diagnosis is established, treatment (the second step) can be initialized. The recommended treatment strategy (also according to EULAR) bases itself on the initial examination by a rheumatologist, preferably within 6 weeks of the onset of joint swelling associated with pain and stiffness. Treatment with conventional synthetic diseasemodifying antirheumatic drugs (csDMARDs) (e.g., methotrexate, unless contraindicated) should start rapidly, aiming to reach either low disease activity or remission as soon as possible (i.e., treat-to-target strategy) $[21,40]$. Norway's treat-to-target prescription guidelines dictate that RA patients only need to fail one type of csDMARDs, such as methotrexate before they can be converted to biological DMARDs (bDMARDs) [27]. As a Norwegian clinical standard, RA patients in remission using DMARDs still require direct observation of treatments and need continuous follow-up by rheumatologists from outpatient clinics or private rheumatologists outside the hospitals.

We suggest that the treatment should be introduced and monitored through the IPU until remission is achieved through validated outcome measures and patient-reported outcome measures. 


\section{Step 3: patient empowered disease management}

Once the status of low disease activity or remission is achieved either through advanced treatments or combination therapy, the patient enters the model's third step. The Patient Empowered Disease Management (PEDM) includes patient-centered methods such as patientcontrolled care, patient-initiated care, and patientmonitored care. Each of these strategies is pivotal in reaching optimal value for RA patients.

The idea behind PEDM is to have the patient govern their illness while acquiring control and mastery in the process. Regaining control over their health is an empowerment method that eventually can lead to a better quality of life and well-being. Furthermore, PEDM may relieve the healthcare providers (HCP) from taking care of the patient throughout their sustained remission (i.e., throughout their life), since through this method, the patient can be given the trust to handle their disease. Indirectly, the PEDM builds a shared responsibility platform between the patients and the HCPs that addresses how to achieve the patient's optimal values together. In advance, the IPU can provide guidance and educate patients to manage their disease and request a follow-up visit when needed. Shared responsibility, self-reporting, and external observation measuring are considering pivotal factors in patient-centered management [41, 42]. Therefore, patients should learn to recognize a disease flare or severe side effects while continuing their treatment. They should also understand their laboratory test better and monitor their disease by using telehealth devices. The PCPs should also be educated using PEDM with the patient and contact the IPU with the patient if any disease status changes occur.

When patients understand the factors affecting their health, they can feel empowered and experience an enhanced quality of life. Having autonomy, knowledge, and control to make these decisions may create stronger self-esteem, better self-affirmation, and directly improve their well-being [24].

\section{Step 4: maintenance through telehealth}

As the final step, while in remission, the informed PEDM-patient should be followed up with telehealth monitoring by rheumatology-specialized nurses or artificial intelligence (AI) algorithms [43, 44]. These qualified nurses or algorithms intend to collaborate with primary healthcare services. Using telehealth technology, a strategy to facilitate follow-up care and ensure that patients with deteriorating diseases can receive appropriate and rapid therapy can be implemented. This strategy can be further enhanced by AI-led software (e.g., chatbots) [43, 44].

Implementing follow-up methods based on prescheduled visits at outpatient clinics in various other chronic inflammatory diseases (e.g., inflammatory bowel diseases) where remission is attainable doubtfully suits with the unpredictable clinical course of the disease [45]. Prescheduled visits can compromise the quality of care and accessibility for the sickest while inefficiently using resources within a healthcare system. However, monitoring these patients through telehealth and implementing self-initiated follow-up could add value to the healthcare systems by improving efficiency and reducing costs without compromising disease outcomes [9, 20, 45]. The reduced utilization of healthcare at the specialist level may release resources allocated to non-responders and provide rapid evaluation for newly diagnosed patients or patients with a disease flare-up [45]. Patients with direct access to rheumatology outpatient clinics resulted in 38\% fewer hospital appointments and better satisfaction and confidence in the system [30].

Patient self-monitoring is a well-accepted and common practice among other chronic diseases (e.g., diabetes, hypertension, and congestive heart failure), supporting decentralized care strategies while improving patient outcomes [46]. Telehealth tools would further facilitate self-monitoring and remote patient surveillance. A double-blind, multicenter, and randomized controlled study with 12 months follow-up showed that monitoring inflammatory bowel disease patients via a telehealth system was safe and reduced outpatient visits and hospital admissions compared with standard care [45].

In tandem, another study found that up to $70 \%$ of patients with RA were reported not to adhere to their prescribed medication [47]. Therefore, telehealth tools may also improve medication compliance by reminding patients to take their prescribed treatments [48].

The use of innovative telehealth tools has also been recommended for close monitoring and follow-up of patients with inflammatory arthritis [49]. For inflammatory arthritis, various remote monitoring tools are in use or being developed with the potential to help improve disease management [49]. Patient-oriented telehealth systems for remote patient monitoring should meet the following: 1. The patient's information on telehealth platforms should be available as reports and on timeview graphs for both patients and HCPs 2. The system should improve drug compliance by reminding patients to take their medication. 3 . The system should make it easy for the patient to communicate with the outpatient clinic. 4. The system should also facilitate the selfadministered booking of visits at the outpatient clinic or the private specialist (e.g., if disease status is deteriorating). 5. The knowledge regarding their disease should be easily accessible at the patients' convenience, including information about symptoms, medication and their side effects, and laboratory values related to disease progression. A randomized study examining RA patients using telehealth monitoring in this manner is currently 
underway. It aims to evaluate disease outcomes and the health-related cost using patient-centeredness through telehealth [50]. Other studies showed a positive effect from using telehealth monitoring of COVID-19 patients [51]. Incorporating telehealth monitoring in COVID-19 patients with an effective managerial strategy may provide early detection of declining health status and efficient use of healthcare resources, and may reduce the need for physical contact with HCPs and subsequently reduce the potential risk of infection [52]. Currently, Norway has an ongoing project to use telehealth monitoring on COVID19 patients isolated at homes and within the hospital. Implementing inpatient-based telehealth on COVID-19 infected patients reduces the infection risk of the HCPs and saves personal protective equipment [53].

\section{Conclusion}

The significant progress in improving RA patient outcomes is the synergy of new treatments and novel therapy strategies coupled with vigilant disease activity monitoring from early diagnosis. With the increased demand for outpatient clinics, the unintended consequences include long waiting lists. This will reduce access to the specialist healthcare system for patients with RA flare-ups, medication side-effects, or new-onset disease.

A decentralized strategy at a national level that addresses routine care to prevent care fragmentation and inefficiencies may be required to mitigate the growing bottle-neck effect for access to outpatient clinics. Implementing the lifelong proposed model focusing on telehealth can maximize high-value care for RA patients by achieving optimal health outcomes at the lowest cost and greater efficiency for the healthcare system. Such a model can be implemented in other settings caring for COVID-19 patients. A corresponding pandemic-IPU can be applied around the COVID-19 patients, where their values are equally addressed in the same manner described above. The model's success may depend on the healthcare system to prioritize the patient's definition of health outcomes in the face of constraints. While our proposed model is illustrated within the Norwegian healthcare system, its applicability to other countries is feasible provided that the objective is to mobilize innovations across existing healthcare systems that could benefit from improved workflow efficiencies.

Amid a growing aging population, advanced RA treatments, yet restricted admissions at hospitals, utilizing a high value-based approach instead of a supply-driven system will be mandatory to sustain healthcare systems. A transformative care delivery model supported by an Integrated Practice Unit could be one approach to decentralize health systems and promote high-value care that matters most to RA patients.

\section{Abbreviations}

Al: Artificial Intelligence; bDMARD: Biological disease-modifying antirheumatic drugs; csDMARD: Conventional synthetic DMARD; EULAR: European League Against Rheumatism; HCP: Healthcare provider; HRQoL: Health-Related Quality of Life; IPU: Integrated Practice Unit; PEDM: Patient Empowered Disease Management; PCP: Primary Care Physician; QoL: Quality of Life; RA: Rheumatoid arthritis

\section{Acknowledgments}

Not applicable.

\section{Authors' contributions}

$A B, A P D, J G K$, and $G H$ discussed the concept and contributed to the manuscript. AB, APD, JGK, and GH drafted and revised the work. AB and APD worked on design and analysis. All authors read and approved the manuscript.

\section{Funding}

No financial support or other benefits from commercial sources for this work have been provided.

Availability of data and materials

Not applicable.

\section{Declarations}

Ethics approval and consent to participate

Not applicable.

Consent for publication

Not applicable.

Competing interests

The authors declare that they have no competing interests.

\section{Author details}

${ }^{1}$ Department of Research, Sorlandet Hospital, Service Box 416, Kristiansand, Norway. ${ }^{2}$ Kaiser Permanente Bernard J. Tyson School of Medicine, Department of Health Systems Science, Pasadena, CA, USA. ${ }^{3}$ Division of Rheumatology, Department of medicine, Sorlandet Hospital, Kristiansand, Norway. ${ }^{4}$ Department of Rheumatology, Martina Hansens Hospital, Bærum (Oslo), Norway. ${ }^{5}$ Division of Rheumatology, Department of Medicine, Akershus University Hospital, Kongsvinger, Norway.

Received: 19 January 2021 Accepted: 7 July 2021

Published online: 08 November 2021

\section{References}

1. Put S, Westhovens R, Lahoutte T, Matthys P. Molecular imaging of rheumatoid arthritis: emerging markers, tools, and techniques. Arthritis Res Ther. 2014;16(2):208. https://doi.org/10.1186/ar4542.

2. Zhou Y, Wang X, An Y, Zhang X, Han S, Li X, et al. Disability and healthrelated quality of life in Chinese patients with rheumatoid arthritis: a crosssectional study. Int J Rheum Dis. 2018;21(9):1709-15. https://doi.org/1 $0.1111 / 1756-185 \times .13345$

3. Whalley D, McKenna SP, de Jong Z, van der Heijde D. Quality of life in rheumatoid arthritis. Br J Rheumatol. 1997;36(8):884-8. https://doi.org/10.1 093/rheumatology/36.8.884.

4. Markusse IM, Akdemir G, Dirven L, Goekoop-Ruiterman YPM, van Groenendael JHLM, Han KH, et al. Long-term outcomes of patients with recent-onset rheumatoid arthritis after 10 years of tight controlled treatment: a randomized trial. Ann Intern Med. 2016;164(8):523-31. https:// doi.org/10.7326/M15-0919.

5. Diamantopoulos AP, Brown TT. Transforming Healthcare in Rheumatology: From Inpatient to Outpatient Care without Reductions in Healthcare Quality [abstract]. Arthritis Rheumatol. 2016;68(suppl 10) https://acrabstracts.org/a bstract/transforming-healthcare-in-rheumatology-from-inpatient-to-outpa tient-care-without-reductions-in-healthcare-quality. Accessed 9 Mar 2020.

6. Kvalvik AG, Larsen S, Aadland HA, Hoyeraal HM. Changing structure and resources in a rheumatology combined unit during 1977-1999. Scand J Rheumatol. 2007;36(2):125-35. https://doi.org/10.1080/03009740600907899. 
7. Haugeberg G, Hansen IJW, Soldal DM, Sokka T. Ten years of change in clinical disease status and treatment in rheumatoid arthritis: results based on standardized monitoring of patients in an ordinary outpatient clinic in southern Norway. Arthritis Res Ther. 2015;17(1):219. https://doi.org/10.1186/ s13075-015-0716-0.

8. Hospital Procurement. [Internet]. [The Health Trusts can save approximately 500 Million on the new Pharmaceutical Agreement]. 2019. Available from: https://sykehusinnkjop.no/nyheter/helseforetakene-kan-spare-ca-500millioner-pa-ny-legemiddelavtale. Accessed 14 May 2020

9. McBain H, Shipley M, Olaleye A, Moore S, Newman S. A patient-initiated DMARD self-monitoring service for people with rheumatoid or psoriatic arthritis on methotrexate: a randomised controlled trial. Ann Rheum Dis. 2016;75(7):1343-9. https://doi.org/10.1136/annrheumdis-2015-207768.

10. Deora H, Sadashiva N, Tripathi M, Yagnick NS, Mohindra S, Batish A, et al. The aftermath of COVID-19 lockdown- why and how should we be ready? Neurol India. 2020;68(4):774-91. https://doi.org/10.4103/0028-3886.293471.

11. Schougaard LMV, Larsen LP, Jessen A, Sidenius $P$, Dorflinger L, de Thurah A, et al. AmbuFlex: tele-patient-reported outcomes (telePRO) as the basis for follow-up in chronic and malignant diseases. Qual Life Res. 2016;25(3):525-34 2016/01/20. Available from: https://pubmed.ncbi. nlm.nih.gov/26790427.

12. de Thurah A, Stengaard-Pedersen K, Axelsen M, Fredberg U, Schougaard LMV, Hjollund NHI, et al. Tele-Health Follow-up Strategy for Tight Control of Disease Activity in Rheumatoid Arthritis: Results of a Randomized Controlled Trial. Arthritis Care Res (Hoboken). 2018;70:353-60.

13. Smith AC, Thomas E, Snoswell CL, Haydon H, Mehrotra A, Clemensen J, et al. Telehealth for global emergencies: implications for coronavirus disease 2019 (COVID-19). J Telemed Telecare. 2020;26(5):309-13. https://doi.org/1 $0.1177 / 1357633 \times 20916567$

14. Mann DM, Chen J, Chunara R, Testa PA, Nov O. COVID-19 transforms health care through telemedicine: evidence from the field. J Am Med Inform Assoc. 2020;27(7):1132-5. https://doi.org/10.1093/jamia/ocaa072.

15. Ohannessian R, Duong TA, Odone A. Global telemedicine implementation and integration within health systems to fight the COVID-19 pandemic: a call to action. JMIR Public Heal Surveill. 2020;6(2):e18810. https://doi.org/1 $0.2196 / 18810$

16. Hong Z, Li N, Li D, Li J, Li B, Xiong W, et al. Telemedicine during the COVID19 pandemic: experiences from Western China. J Med Internet Res. 2020; 22(5):e19577. https://doi.org/10.2196/19577.

17. Contreras CM, Metzger GA, Beane JD, Dedhia PH, Ejaz A, Pawlik TM Telemedicine: patient-provider clinical engagement during the COVID-19 pandemic and beyond. J Gastrointest Surg Off J Soc Surg Aliment Tract. 2020;24(7):1692-7. https://doi.org/10.1007/s11605-020-04623-5.

18. Wynn R. E-health in Norway before and during the initial phase of the Covid-19 pandemic. Stud Health Technol Inform. 2020;272:9-12. https://doi. org/10.3233/SHTI200480.

19. Porter ME. What is value in health care? N Engl J Med. 2010;363(26):247781. https://doi.org/10.1056/NEJMp1011024

20. Porter ME, Lee TH. Why strategy matters now. N Engl J Med. 2015;372(18): 1681-4. https://doi.org/10.1056/NEJMp1502419.

21. Combe B, Landewe R, Daien $\mathrm{Cl}$, Hua C, Aletaha D, Alvaro-Gracia JM, et al. 2016 update of the EULAR recommendations for the management of early arthritis. Ann Rheum Dis. 2017;76(6):948-59. https://doi.org/10.1136/a nnrheumdis-2016-210602.

22. Fayers P. Quality of life: the assessment, analysis and interpretation of patient-reported outcomes. 2nd ed. Chichester: John Wiley \& Sons; 2007. Print. https://abdn.pure.elsevier.com/en/publications/quality-of-life-the-a ssessment-analysisand-interpretation-of-pat.

23. Nordenfelt L. Quality of life, health and happiness. Avebury: Ashgate Publishing Limited; 1993. Print

24. Tengland P-A. Empowerment: a goal or a means for health promotion? Med Health Care Philos. 2007;10:197-207. https://doi.org/10.1007/s11019006-9027-1.

25. Dooher J. Empowerment and participation: power influence and control in contemporary healthcare. Wiltshire: Quay Books; 2002. Print

26. Clement-Carbonell V, Ferrer-Cascales R, Ruiz-Robledillo N, Rubio-Aparicio M, Portilla-Tamarit I, Cabañero-Martínez MJ. Differences in autonomy and health-related quality of life between resilient and non-resilient individuals with mild cognitive impairment. Int J Environ Res Public Health. 2019;16(13). https://doi.org/10.3390/ijerph16132317.
27. Sharma U, Clarke M. Nurses' and community support workers' experience of telehealth: a longitudinal case study. BMC Health Serv Res. 2014;14(1):164 https://doi.org/10.1186/1472-6963-14-164.

28. McLean S, Sheikh A, Cresswell K, Nurmatov U, Mukherjee M, Hemmi A, et al. The impact of telehealthcare on the quality and safety of care: a systematic overview. PLoS One. 2013;8(8):e71238. https://doi.org/10.1371/journal.pone. 0071238.

29. Hjelm NM. Benefits and drawbacks of telemedicine. J Telemed Telecare. 2005;11(2):60-70. https://doi.org/10.1258/1357633053499886.

30. Hewlett S, Kirwan J, Pollock J, Mitchell K, Hehir M, Blair PS, et al. Patient initiated outpatient follow up in rheumatoid arthritis: six year randomised controlled trial. BMJ. 2005;330:171.

31. Ajeganova S, Huizinga T. Sustained remission in rheumatoid arthritis: latest evidence and clinical considerations. Ther Adv Musculoskelet Dis. 2017;9(10): 249-62. https://doi.org/10.1177/1759720X17720366.

32. Howren A, Tsao NW, Choi HK, Shojania K, Kydd A, Friesen R, et al. eHealthsupported decentralized multi-disciplinary care for gout involving rheumatology, pharmacy, and dietetics: proof-of-concept study. Clin Rheumatol. 2020;39(4):1241-9. https://doi.org/10.1007/s10067-019-04809-6.

33. Kataria S, Ravindran V. Digital health: a new dimension in rheumatology patient care. Rheumatol Int. 2018;38(11):1949-57. https://doi.org/10.1007/ s00296-018-4037-x.

34. Buvik A, Bugge E, Knutsen G, Småbrekke A, Wilsgaard T. Quality of care for remote orthopaedic consultations using telemedicine: a randomised controlled trial. BMC Health Serv Res. 2016;16(1):483. https://doi.org/10.1186/ s12913-016-1717-7.

35. Fox MP, Pascoe S, Huber AN, Murphy J, Phokojoe M, Gorgens M, et al. Adherence clubs and decentralized medication delivery to support patient retention and sustained viral suppression in care: results from a clusterrandomized evaluation of differentiated ART delivery models in South Africa. PLoS Med. 2019;16(7):e1002874. https://doi.org/10.1371/journal. pmed.1002874.

36. Trondsen MV, Bolle SR, Stensland G $\varnothing$, Tjora A. VIDEOCARE: decentralised psychiatric emergency care through videoconferencing. BMC Health Serv Res. 2012;12(1):470. https://doi.org/10.1186/1472-6963-12-470.

37. Dhiman RK, Grover GS, Premkumar M, Taneja S, Duseja A, Arora S, et al. Decentralized care with generic direct-acting antivirals in the management of chronic hepatitis C in a public health care setting. J Hepatol. 2019;71(6): 1076-85. https://doi.org/10.1016/j.jhep.2019.07.006.

38. Menon SS, Rossi R, Nshimyumukiza L, Zinszer K. Decentralized control of human visceral leishmaniasis in endemic urban areas of Brazil: a literature review. Trop Med Health. 2016;44(1):9. https://doi.org/10.1186/s41182-0160011-z.

39. Uhlig T, Bjørneboe O, Krø\|l F, Palm Ø, Olsen IC, Grotle M. Involvement of the multidisciplinary team and outcomes in inpatient rehabilitation among patients with inflammatory rheumatic disease. BMC Musculoskelet Disord. 2016;17(1):18. https://doi.org/10.1186/s12891-016-0870-9.

40. Smolen JS, Landewé RBM, Bijlsma JWJ, Burmester GR, Dougados M, Kerschbaumer A, et al. EULAR recommendations for the management of rheumatoid arthritis with synthetic and biological disease-modifying antirheumatic drugs: 2019 update. Ann Rheum Dis. 2020;79:685 LP-699. https://doi.org/10.1136/annrheumdis-2019-216655.

41. Mead N, Bower P. Patient-centredness: a conceptual framework and review of the empirical literature. Soc Sci Med. 2000;51(7):1087-110. https://doi. org/10.1016/S0277-9536(00)00098-8.

42. Constand MK, MacDermid JC, Dal Bello-Haas V, Law M. Scoping review of patient-centered care approaches in healthcare. BMC Health Serv Res. 2014 14(1):271. https://doi.org/10.1186/1472-6963-14-271.

43. Pacis DMM, Subido EDC, Bugtai NT. Trends in telemedicine utilizing artificial intelligence. AIP Conf Proc. 2018;1933:40009. https://doi.org/10.1063/1.5023979.

44. Kuziemsky C, Maeder AJ, John O, Gogia SB, Basu A, Meher S, et al. Role of artificial intelligence within the telehealth domain: official 2019 yearbook contribution by the members of IMIA telehealth working group. Yearb Med Inform. 2019:28(1):35-40 https://doi.org/10.1055/s-0039-1677897.

45. de Jong MJ, van der Meulen-de Jong AE, Romberg-Camps MJ, Becx MC, Maljaars JP, Cilissen M, et al. Telemedicine for management of inflammatory bowel disease (mylBDcoach): a pragmatic, multicentre, randomised controlled trial. Lancet (London, England). 2017:390:959-68.

46. Smolen JS, Breedveld FC, Burmester GR, Bykerk V, Dougados M, Emery P, et al. Treating rheumatoid arthritis to target: 2014 update of the 
recommendations of an international task force. Ann Rheum Dis. 2016;75(1): 3-15. https://doi.org/10.1136/annrheumdis-2015-207524.

47. Salt E, Frazier SK. Adherence to disease-modifying antirheumatic drugs in patients with rheumatoid arthritis: a narrative review of the literature. Orthop Nurs. 2010;29(4):260-75. https://doi.org/10.1097/NOR.0b013e3181 e5c2c9.

48. dos Santos MVR, de Oliveira DC, de Araújo Novaes M. A telehealth strategy for increasing adherence in the treatment of hypertension in primary care. Telemed J e-health Off J Am Telemed Assoc. 2013;19:241-7.

49. van Riel $P$, Alten $R$, Combe $B$, Abdulganieva D, Bousquet $P$, Courtenay $M$, et al. Improving inflammatory arthritis management through tighter monitoring of patients and the use of innovative electronic tools. RMD Open. 2016;2(2):e000302. https://doi.org/10.1136/rmdopen-2016-000302.

50. ClinicalTrials.gov [Internet]. Bethesda (MD): National Library of Medicine (US). 2000 Feb 29. Identifier NCT04536844, Telehealth Follow-up in Patients with Rheumatoid; 2020 Sept 3 [cited 2021 May 05]. Available from: https://www. clinicaltrials.gov/ct2/show/NCT04536844.

51. Martínez-García M, Bal-Alvarado M, Santos Guerra F, Ares-Rico R, Suárez-Gil R, Rodríguez-Álvarez A, et al. Monitoring of COVID-19 patients by telemedicine with telemonitoring $\Pi$ - Telemedicina con telemonitorización en el seguimiento de pacientes con COVID-19. Rev Clin Esp. 2020;220(8): 472-9. https://doi.org/10.1016/.j.re.2020.05.013.

52. Silven AV, Petrus AHJ, Villalobos-Quesada M, Dirikgil E, Oerlemans CR, Landstra CP, et al. Telemonitoring for patients with COVID-19: recommendations for design and implementation. J Med Internet Res. 2020; 22(9):e20953. https://doi.org/10.2196/20953.

53. Norwegian Broadcasting Corporation. [Internet]. [The way COVID-19 patient May-Lill was followed up attracts attention - now the WHO wants to know more]. Nov 2020. Available from: https://www.nrk.no/nordland/korona_verdens-helseorganisasjon-who-vil-laere-av-bodo-om-oppfolging-av-korona pasienter-i-isolasjon-1.15238573. Accessed 05 May 2021.

\section{Publisher's Note}

Springer Nature remains neutral with regard to jurisdictional claims in published maps and institutional affiliations.

Ready to submit your research? Choose BMC and benefit from:

- fast, convenient online submission

- thorough peer review by experienced researchers in your field

- rapid publication on acceptance

- support for research data, including large and complex data types

- gold Open Access which fosters wider collaboration and increased citations

- maximum visibility for your research: over $100 \mathrm{M}$ website views per year

At $\mathrm{BMC}$, research is always in progress.

Learn more biomedcentral.com/submissions 